\title{
Maize Leaf Epiphytic Bacteria Diversity Patterns Are Genetically Correlated with Resistance to Fungal Pathogen Infection
}

\author{
Peter Balint-Kurti, ${ }^{1}$ Susan J. Simmons, ${ }^{2}$ James E. Blum, ${ }^{2}$ Carlos L. Ballarée, ${ }^{3}$ and Ann E. Stapleton ${ }^{4}$ \\ ${ }^{1}$ United States Department of Agriculture-Agricultural Research Service and Department of Plant Pathology, North Carolina \\ State University, Raleigh, NC, U.S.A.; ${ }^{2}$ Department of Mathematics and Statistics, University of North Carolina at Wilmington, \\ Wilmington, NC, U.S.A.; ${ }^{3}$ IFEVA-Facultad de Agronomía, Consejo Nacional de Investigaciones Científicas y Técnicas, and \\ Universidad de Buenos Aires, Avenida San Martín 4453, C1417DSE Buenos Aires, Argentina, ${ }^{4}$ Department of Biology and \\ Marine Biology, University of North Carolina at Wilmington
}

Submitted 23 July 2009. Accepted 25 November 2009.

Plant leaves host a specific set of microbial epiphytes. Plant genetic and solar UV-B radiation effects on the diversity of the phyllosphere were examined by measuring epiphytic bacterial ribosomal DNA diversity in a maize recombinant inbred (RI) mapping population. Several chromosomal quantitative trait loci (QTL) with significant effects on bacterial diversity were identified, some of which had effects only in the presence of UV-B radiation and others that had effects both with and without UV-B. Candidate genes with allele-specific effects were mapped to the bacterial diversity chromosomal regions. A glutamate decarboxylase candidate gene was located at a UV-B-specific chromosomal locus, and in a comparison between two RI lines with contrasting bacterial diversity phenotypes, high bacterial diversity was associated with high levels of glutamate decarboxylase enzyme activity, a component of the gamma-aminobutyric acid (GABA) pathway. The bacterial diversity loci exhibited a significant overlap with loci connected with Southern leaf blight (SLB) susceptibility in the field. A SLB-resistant inbred genotype had less beta bacterial diversity, and antibiotic treatment of inbreds increased this diversity. These results suggest that the GABA pathway is genetically associated with phyllosphere bacterial diversity. Furthermore, the colocalization of QTL between low bacterial diversity and fungal blight-resistance and the increase in beta diversity in antibiotic-treated leaves suggest that occupation of leaf habitats by a particular set of suppressive bacteria may restrict phyllosphere bacterial variability and increase resistance to fungal infection.

The terrestrial leaf surface is a principal microbial habitat, covering approximately $10^{8} \mathrm{~km}^{2}$ with an estimated $10^{26}$ bacterial cells (Lindow and Brandl 2003). Microbial species known in this habitat include members of the major bacterial and fun-

Corresponding author: Ann E. Stapleton: stapletona@uncw.edu

*The $\boldsymbol{e}$-Xtra logo stands for "electronic extra" and indicates that two supplementary tables, one supplementary figure, and supplementary design and analysis information are published online. Figure 4 also appears in color online.

This article is in the public domain and not copyrightable. It may be freely reprinted with customary crediting of the source. The American Phytopathological Society, 2010. gal groups, with few culturable species and many ribotypes (i.e., ribosomal RNA gene segments with size and sequence differences) known only from molecular characterization (de Jager et al. 2001; Heuer and Smalla 1999; Idris et al. 2004; Kadivar and Stapleton 2003; Kim et al. 1998; Yang et al. 2001). Sources of bacteria inhabiting the phylloplane have not yet been examined with molecular methods; for culturable bacteria, it has been determined that new plant hosts derive their microbial communities from other plant leaves, with relatively little limit on the distance from the source leaves (Upper et al. 2003). Limited evidence from direct comparison of phyllosphere and rhizosphere communities by culture-independent methods supports the previous culture-based method conclusions that phyllosphere diversity is lower than the very complex microbial communities found in soils and soil microbe communities differ substantially from epiphytic ones (Ibekwe and Grieve 2004). Most of the research on phyllosphere communities has focused on culturable species or on pathogen and beneficial growth-promoting interactions with plant hosts (Compant et al. 2005; Everett et al. 2005; Hirano and Upper 2000; Lindow and Brandl 2003; Whipps et al. 2008).

Leaf epiphytes compete for resources in an environment with rapid and extreme variation in temperature, UV radiation, and water availability (Lindow and Brandl 2003). Carbon is considered to be the limiting nutritional factor for bacterial growth (Mercier and Lindow 2000), although a promoter-trapping strategy implemented in Pseudomonas syringae also suggests that sulfur limitation is important (Marco et al. 2005). The microstructure of leaves can affect the type and pattern of colonization by bacteria, including the formation of aggregates or biofilms (Beattie and Lindow 1999; Karamanoli et al. 2005; Kinkel et al. 2000; Ramey et al. 2004). The microstructure and chemical characteristics of the host plant can differ due to genotype or be altered by the actions of epiphytes (Fiala et al. 1990; Schreiber et al. 2005; Whipps et al. 2008).

Corn, Zea mays L., is one of the most widely grown and economically important annual crops. Corn acreage in the U.S. covers about 32 million hectares per year (Baker 2005). There is an opportunity for millions of bacteria and fungi to colonize corn leaves each year. We have very little information about colonization and persistence of nonpathogenic microbes on this extensive habitat and their interactions with pathogenic microorganisms. Fungi probably constitute the most important group of corn pathogens (Smith and White 1988). One wellknown pathogen important in warm humid regions is Southern 
leaf blight (SLB), caused by Cochliobolus heterostrophus (Drechs.) Drechs. (anamorph = Bipolaris maydis (Nisikado) Shoemaker; synonym = Helminthosporium maydis Nisikado). This pathogen caused extensive yield loss in the early 1970s in the southern U.S., due to the presence of a specific cytoplasmic gene, which was present in many commercial hybrids at that time, that conferred extreme susceptibility (Ullstrup 1972). Substantial mapping and breeding efforts are directed at understanding the genetic architecture of maize disease resistance (Balint-Kurti et al. 2007; Wisser et al. 2006). However, the focus has been on direct genetic determinants of plant resistance.

The connections between plant bacterial diversity and disease resistance have not been previously examined in maize. Treatments with antagonist bacterial strains, which inhibit or suppress the growth of pathogenic microorganisms, are widely used for biological control of a variety of diseases in horticultural and fruit crop production (Johnson and Stockwell 1998; Lindow and Suslow 2003; Ojiambo and Scherm 2006; Stockwell and Stack 2007) and may be feasible in rice (De Costa et al. 2006a). A better understanding of the effects of plant genotype on interactions between pathogenic and nonpathogenic phyllosphere microorganisms could facilitate future breeding efforts for enhanced disease resistance.

The study of genetic constraints on microbial interactions has been integrated into a new area, community genetics (Whitham et al. 2003). Genetic effects of poplar host trees on communities at other trophic levels, including microbial communities (Schweitzer et al. 2006), indicate that host genotype provides substantial contributions to trophic-level variation in community structure. De Costa and asssociates (2006a and b) have found that leaves from different rice genotypes have different culturable bacterial communities; apple cultivars are also known to confer differences in bacterial survival (Gau et al. 2002). Rhizobacterial populations assayed using culture methods differ between maize parent lines and hybrids, with hybrids having a higher diversity of Pseudomonads (Picard and Bosco 2005). Culturable rhizosphere bacteria were examined in tomato mapping lines, and the tomato host plant loci controlling rhizosphere populations were mapped (Smith et al. 1999). Stapleton and Simmons (2006) described comparisons between inbred and hybrid maize phyllospheres and found that the effects of an environmental stressor, UV-B, on phyllosphere bacterial community diversity were dependent on the genotype of the host plant. One possible mechanism for such genotype effects is through changes in leaf chemistry. Arabidopsis thaliana mutants defective in accumulation of the defense hormone jasmonic acid had increased epiphytic culturable bacterial diversity (Kniskern et al. 2007). Plants also produce molecules that alter bacterial quorum sensing, such as acyl-homoserine lactones (Pierson and Pierson 2007) and gamma-amino butyric acid (GABA) (Chevrot et al. 2006), and variation among genotypes in the abundance of these substances could affect microbial communities.

Functional consequences of variations in phyllosphere diversity are not yet clear (Whipps et al. 2008). From an ecological perspective, we expect diversity differences to have consequences for extent of pathogen spread and intensity of pathogen pressure as well as feedback effects on the host plant (Prosser et al. 2007). One way to begin to understand the determinants of epiphytic diversity and its functional consequences is to look for genetic correlations, using tools such as quantitative trait loci (QTL) mapping populations (Lynch and Walsh 1998). QTL analysis is used for initial identification of chromosomal loci for the ultimate goal of localization of causative nucleotide changes ("QTL cloning") and for comparison of the genetic architecture of traits to reveal possible underlying genetic correlations.
We hypothesized that specific loci in the host affected microbial phyloplane diversity and, furthermore, that these effects would interact with abiotic stresses imposed on the leaf. In order to test this hypothesis, we measured the diversity of epiphytic bacterial ribosomal DNA in a maize advanced intercrossed mapping population with and without solar UV-B radiation. We used UV-B as a model environmental stressor because previous studies have shown that phyllosphere diversity is affected by UV-B radiation (Kadivar and Stapleton 2003; Moody et al. 1999; Newsham et al. 1997; Robson et al. 2004) and because there is abundant evidence that current levels of UV-B may have strong influences on the interactions between plants and organisms of other trophic levels, including pathogenic microorganisms (Gunasekera and Paul 2007; Gunasekera et al. 1997), decomposers (Pancotto et al. 2003), microfauna (Searles et al. 1999; Searles et al. 2001), and canopy arthropods (Ballaré et al. 1996; Mazza et al. 1999; Caputo et al. 2006). We observed consistent differences among genotypes in the diversity of the epiphytic microbial population and found six loci that control epiphytic diversity. Strikingly, these loci had a significant overlap with maize loci controlling resistance to SLB. Candidate genes in the diversity QTL regions were identified, and results of enzyme activity assays were consistent with a role for glutamate decarboxylase. Additional testing of inbred genotypes and manipulation of leaf epiphytic bacterial populations through antibiotic treatment supported the genetic correlation between leaf bacterial diversity and disease susceptibility.

\section{RESULTS}

\section{Chromosomal loci for bacterial diversity.}

Microbial phyllosphere diversity was measured on selected members of the maize IBM recombinant inbred (RI) mapping population with and without UV radiation (described below). Genetic factors and UV-B exposure both affected the amount of microbial community diversity on maize leaves. We measured diversity using the Simpson-diversity index, which ranges between 0 and 1, with larger values indicating greater diversity. Both the number of different ribotypes identified in a sample (the richness) and the amount of the ribotype in the sample (the evenness) contribute to increasing the value of the Simpson-diversity measure. Maize phyllosphere bacterial ribotypes, as identified by terminal-restriction fragment length polymorphism (T-RFLP) or automated ribosomal intergenic spacer analysis (ARISA), were counted using profile-processing tools, as described below, and individual ribotypes (also known as operational taxonomic units) were used in place of the classical taxonomic species designation in calculation of these indices.

We found six maize chromosomal regions that control epiphytic diversity, as evaluated using the Simpson-diversity index to summarize T-RFLP profiles of bacterial diversity. Three of the loci, in map bins 1.06-1.07, 6.04-6.05, and 9.05, were UV-B environment-specific (in other words, their effects were only seen in the presence of UV-B radiation [Fig. 1]), whereas the other three had significant effects on Simpson diversity regardless of UV-B radiation treatment (in other words, these QTL were detected both in conditions with and without UV-B radiation [Fig. 2]). Additional QTL for Simpson diversity are listed in Supplemental Table 1; these loci were selected with more liberal threshold values of 0.05 and thus have a higher probability of false-positive association. Based on our previous work with the inbred parents of the mapping populations, we expected to see genotype by UV-environment variation (Stapleton and Simmons 2006) and, indeed, the variance component for genotype X UV treatment was the highest. Compari- 
son of our Simpson-diversity QTL with literature reports revealed one striking overlap in QTL locations; maize loci controlling Southern leaf blight (SLB) resistance in the field (Balint-Kurti et al. 2007) are colocated with the Simpson bacterial diversity QTL. A detailed locus-by-locus comparison is included in Supplementary Text.

\section{Candidate genes in QTL regions.}

Relatively large regions of the genome are defined by QTL, and priorities for follow-up mechanistic studies are set through examination of gene annotations and expression in these QTL genomic areas. It is especially interesting to consider genes at the loci for which the parental alleles show expression-level differences. One caveat is that these different levels of expression may be caused by trans factors that are not located in the QTL region (Kleibenstein 2009). Therefore, it is important to verify that the loci controlling these differences in expression (also known as expression QTL or eQTL) are closely linked ("in cis with") the genes themselves. In previous work using a subset of IBM lines, we had identified cis-eQTL for differentially expressed alleles along the maize genome (Harjes et al. 2008; A. E. Stapleton, unpublished results). Table 1 shows an eQTL candidate list for the genome regions identified as Simpson-diversity QTL. Some QTL regions only had a few eQTL (such as the region in chromosome bin 9.06), while for others, there was significant segregation disequilibrium with other chromosomal regions that precluded eQTL detection (such as the chromosome bin 1.06 [ctg41] region). In order to further search for candidate genes in the chromosomal regions spanning the diversity QTL, we also examined the maize genome annotations in each region individually, without consideration of the presence of eQTL.

From inspection of the public maize genome sequence in the QTL regions, we localized one especially notable gene, glutamate decarboxylase, in the chromosome bin 1.06 QTL region. Glutamate decarboxylase is the first committed step in the syn-
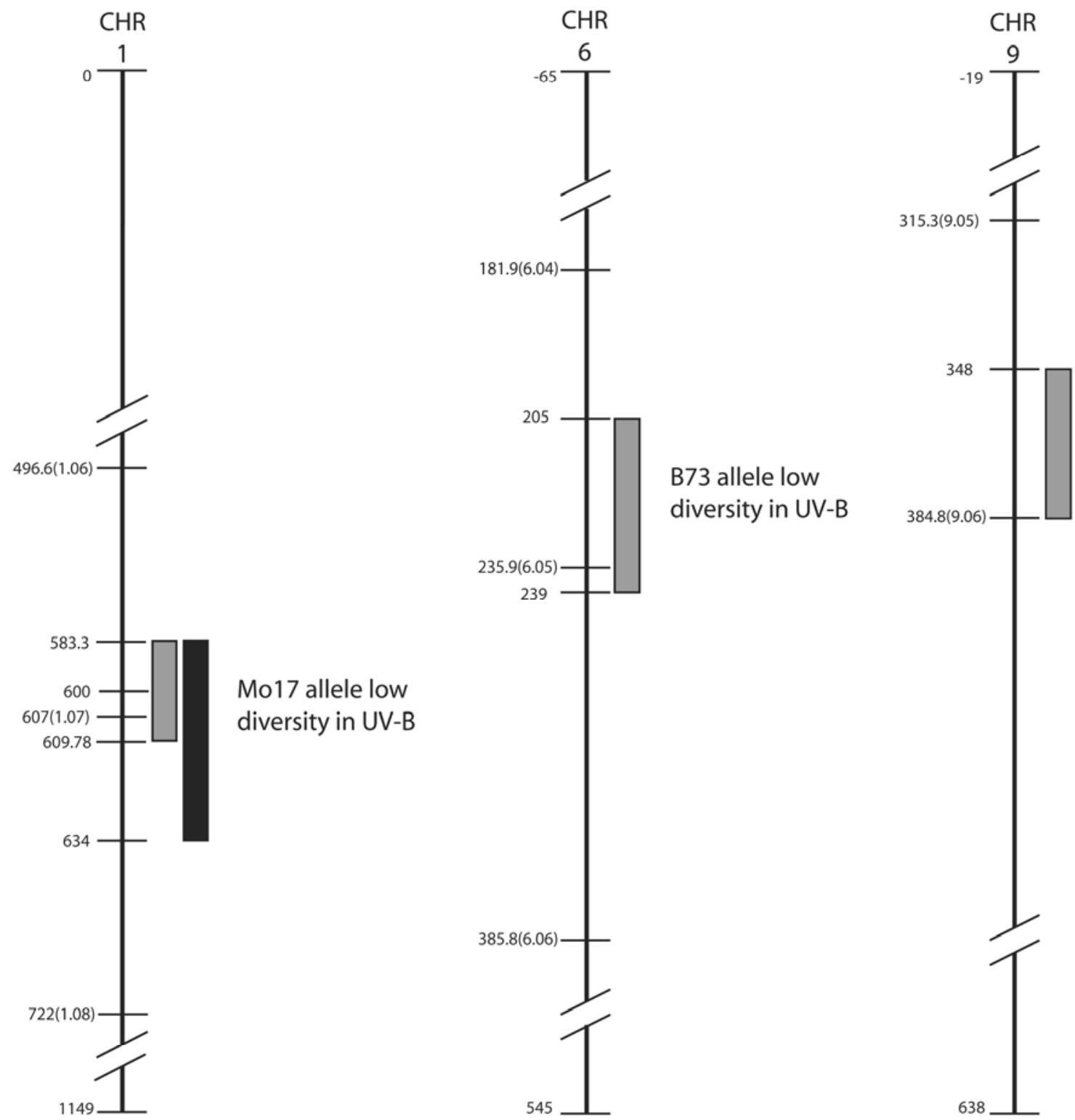

B73 allele low diversity in UV-B

Fig. 1. Bacterial leaf diversity quantitative trait loci (QTL) locations on maize chromosomes for loci with a significant UV treatment-marker locus interaction (environmental interaction, $\mathrm{G} \times \mathrm{E}$, i.e., they are detected only in the presence of UV-B radiation). Loci found using GLM ChromoScan are indicated with gray bars to the right of the chromosome. Loci detected using QTLNetwork are indicated with black bars. Map distances are from the IBM2 Neighbors 2005 map in centiMorgans; map bins are indicated in parentheses at the beginning of the bin region. For clarity, only the chromosome regions near QTL are shown, with breaks in the vertical bar for each chromosome indicating the map position of the entire remainder of that chromosome. 
thesis of GABA. GABA has been implicated in interactions between plants and a variety of organisms, including closely associated microorganisms (Shelp et al. 2006).

\section{Glutamate decarboxylase activity \\ in extreme RI lines.}

Identification of glutamate decarboxylase as a candidate gene in the chromosome 1 UV-B-dependent Simpson-diversity QTL region prompted further analysis of glutamate decarboxylase enzyme activity in RI mapping lines that had the highest and lowest bacterial diversity, as evaluated using the Simpson index, and that had opposite parental alleles (Mo17 parent versus B73 parent) at the chromosome bin 1.06-1.07 markers near the glutamate decarboxylase gene. These extreme lines were grown in the field under summer high-UV-B conditions with high levels of SLB pathogen pressure. We measured glutamate decarboxylase activity in leaf samples by amino-acid profiling and found a positive association, with the high-Simpson-diversity, SLB-sensitive line having high levels of glutamate decarboxylase activity (Fig. 3).

\section{Genotype and antibiotic experiment analysis.}

Mapping experiments identify statistical associations between phenotypes and chromosomal loci but do not demonstrate causative relationships. Therefore, manipulative experiments are a useful follow-up to mapping. As typical genetic tools such as tiled near-isogenic lines and insertion mutants are not yet publicly available for maize, we focused on manipulating the microbial community. Antibiotics have been used to manipulate bacterial populations in soils (Demoling et al. 2009; Muller et al. 2002; Piotrowska et al. 2008; Westergaard et al. 2001). We manipulated maize leaf bacterial populations using exogenous antibiotic treatment, spraying streptomycin sulfate at two different concentrations on leaves in the field
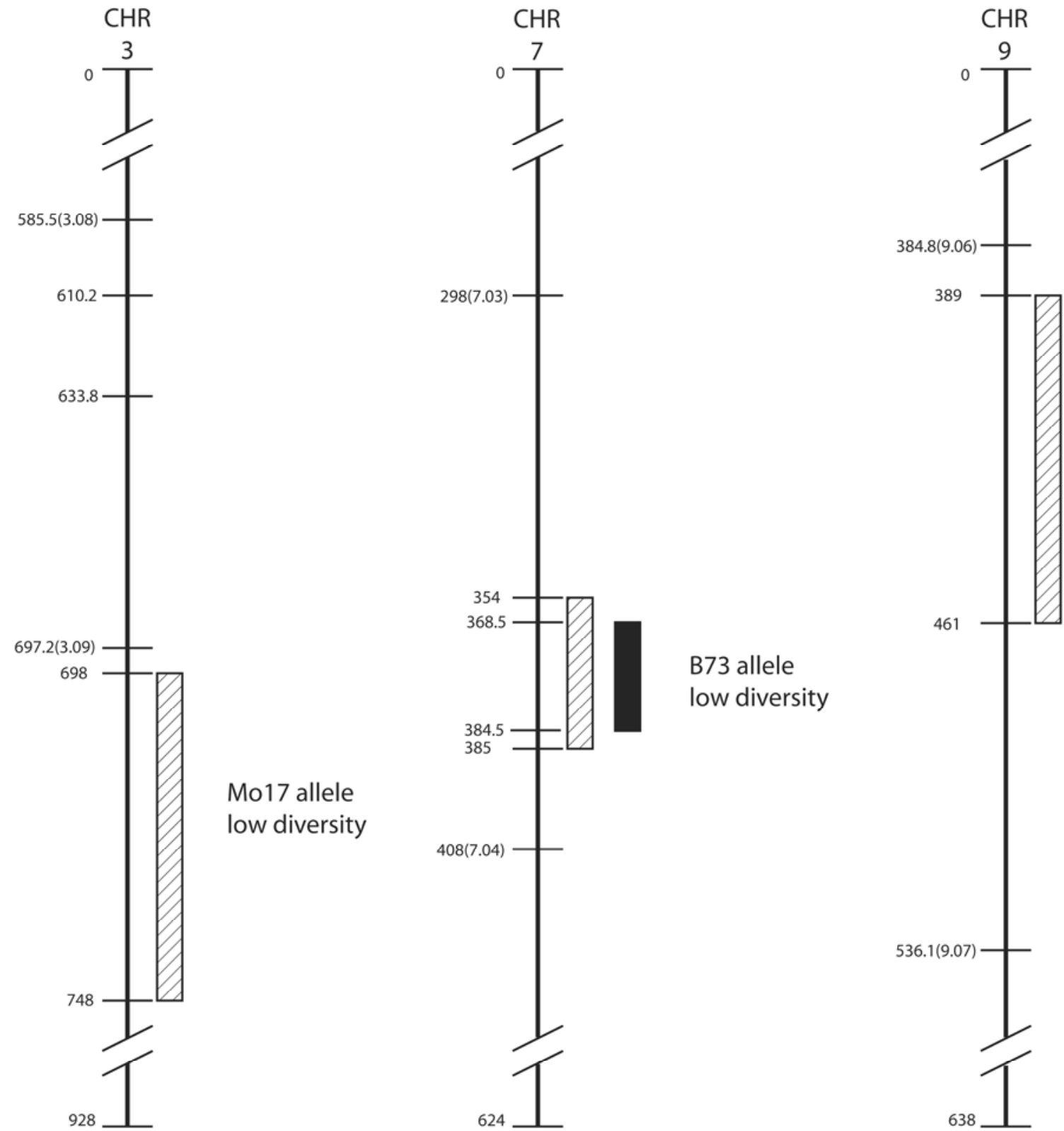

B73 allele

low diversity

Fig. 2. Bacterial leaf diversity quantitative trait loci (QTL) locations that show significant association with a marker allele but no UV-B treatment $(\mathrm{G} \times \mathrm{E})$ effect (i.e., they are detected both in the presence and the absence of UV-B radiation). Loci found using GLM ChromoScan are indicated with diagonally striped bars to the right of the chromosome. Loci detected using QTLNetwork are indicated with black bars. Map distances are from the IBM2 Neighbors 2005 map in centiMorgans; map bins are indicated in parentheses at the beginning of each bin region. For clarity, only the chromosome regions near QTL are shown, with breaks in the vertical bar for each chromosome indicating the map position of the entire remainder of that chromosome. 
(0.1 g/liter for low strep, $0.4 \mathrm{~g} /$ liter for high strep). We also examined genotypic differences by using inbred lines with different pathogen susceptibility. A factorial complete block experiment was used to test the effect of maize inbred genotypes and antibiotic treatment on leaf bacterial diversity. This factorial design allowed us to measure bacterial diversity in multivariate detail, rather than condensing the different types of diversity into an index. Both alpha diversity (difference in number of ribotypes) and beta diversity (difference in overall leaf microbial community composition, i.e., how different the samples are from each other across the experiment) were examined in these phyllosphere bacterial samples.

Using the multivariate dispersion as a measure of beta diversity, we found that the more SLB-resistant inbred Mo17 had less beta diversity than did B73 (Table 2). With streptomycin antibiotic treatment, the multivariate dispersion increased for both lines (Table 2). There was no significant interaction, which indicates that both B73 and Mo17 leaf samples increased to about the same extent in bacterial beta diversity after antibiotic treatment. We also tested for differences in alpha diversity, using a test called the adjusted analysis of similarity test (ANOSIM) that adjusted for differences in beta diversity. The ANOSIM analysis showed no significant effect of antibiotic (significance level of sample statistic 0.87 ) on alpha diversity. In other words, the total number of bacterial ribotypes on leaves after antibiotic spray was not significantly changed, although the community composition, the beta diversity, was different.

There was a suggestive difference between genotypes by ANOSIM (significance level equal to 0.099) with more ribotypes present on Mo17 (421 ribotypes) than on B73 (274 ribotypes). SIMPER analysis examines the contribution of each species to the average dissimilarity between groups of samples and determines the contribution to similarity within a group. In our case, SIMPER can be used to compare the contribution of individual ribotypes to differences in phyllosphere diversity on

Table 1. $c i s$-Located genes with significant diversity-quantitative trait loci (QTL) associations

\begin{tabular}{|c|c|c|c|c|}
\hline Bin & Fpc contig $^{y}$ & Strength $^{\mathrm{z}}$ & Gene array ID & Annotation \\
\hline \multicolumn{5}{|c|}{ UV-B-specific diversity QTL } \\
\hline \multirow[t]{19}{*}{6.04} & $279,280,281$ & 0.13 & MZ00019566 & G-protein coupled receptor IPR000848 \\
\hline & & 0.2 & MZ00021863 & Calcium-binding EF hand \\
\hline & & 0.13 & MZ00023496 & Similar to 40 S ribosomal protein $\mathrm{S} 17$ \\
\hline & & 0.53 & MZ00038116 & Ribosomal protein S17 IPR001210 \\
\hline & & 0.13 & MZ00040529 & Hypothetical protein \\
\hline & & 0.13 & MZ00051052 & Hypothetical protein \\
\hline & & 0.13 & MZ00005058 & NA \\
\hline & & 0.13 & MZ00007627 & C2 Armadillo fold IPR000225 \\
\hline & & 0.13 & MZ00011052 & Glutaredoxin-related \\
\hline & & 0.2 & MZ00012652 & Putative zinc finger \\
\hline & & 0.2 & MZ00020698 & FACT complex subunit \\
\hline & & 0.53 & MZ00024893 & Abcisic-acid induced HVA22/DPI IPR004345 \\
\hline & & 0.2 & MZ00026199 & Hypothetical protein \\
\hline & & 0.26 & MZ00028774 & Putative glycosyl hydrolase \\
\hline & & 0.26 & MZ00029723 & Phosphoribosyltransferase IPR000836 \\
\hline & & 0.2 & MZ00031599 & Unknown protein \\
\hline & & 0.2 & MZ00039834 & BH3/fasciclin IPR000782 \\
\hline & & 0.13 & MZ00043265 & Putative pyrophosphate-dependent phosphofructokinase beta subunit \\
\hline & & 0.13 & MZ00055806 & Unknown protein \\
\hline \multirow[t]{4}{*}{9.05} & 386,387 & 0.14 & MZ00001457 & Novel transcript \\
\hline & & 0.14 & MZ00005106 & Zinc finger IPR002893 \\
\hline & & 0.21 & MZ00005214 & Hydroxyproline-rich glycoprotein \\
\hline & & 0.21 & MZ00022697 & Haem-oxygenase-like IR016084 \\
\hline \multicolumn{5}{|c|}{ Non-UV-B diversity QTL } \\
\hline \multirow[t]{8}{*}{3.09} & 148,149 & 0.21 & MZ00003537 & Zinc finger IPR001841 \\
\hline & & 0.21 & MZ00056046 & Antifreeze protein IPR000104 \\
\hline & & 0.21 & MZ00005019 & Amino acid transporter IPR013057 \\
\hline & & 0.21 & MZ00008487 & Beta-adaptin-like protein \\
\hline & & 0.11 & MZ00031398 & Putative DNA-binding protein \\
\hline & & 0.21 & MZ00044520 & Recoverin IPR001125 \\
\hline & & 0.21 & MZ00051083 & Heat shock transcription factor HSF8-like \\
\hline & & 0.16 & MZ00055745 & Calcineurin-B-like protein 9 \\
\hline \multirow[t]{14}{*}{7.03} & $320,321,322$ & 0.77 & MZ00010924 & SET-domain transcript \\
\hline & & 0.82 & MZ00011308 & Signal peptidase IPR007653 \\
\hline & & 0.91 & MZ00015134 & Serine carboxypeptidase \\
\hline & & 0.41 & MZ00021775 & Hypothetical protein \\
\hline & & 0.82 & MZ00025972 & Unknown protein \\
\hline & & 0.64 & MZ00029810 & Tetratricopeptide IPR013026 \\
\hline & & 0.73 & MZ00031390 & Endonuclease IPR005135 \\
\hline & & 0.82 & MZ00031440 & SET IPR001214 \\
\hline & & 0.5 & MZ00032539 & Unknown protein DUF284 \\
\hline & & 0.59 & MZ00032688 & Dopamine beta mono-oxygenase \\
\hline & & 0.23 & MZ00051157 & Putative GTP-binding protein \\
\hline & & 0.73 & MZ00029634 & Chromodomain helicase \\
\hline & & 0.72 & MZ00048797 & Putative glucosyl transferase \\
\hline & & 0.36 & MZ00051593 & Putative MATE efflux protein \\
\hline
\end{tabular}

${ }^{\mathrm{y}}$ Fingerprint (fpc) contigs were localized from the maize physical map (Maizesequence, vs. 3b.50), using the genetic markers. These are, thus, the current best estimates of the physical location of the genes under the Simpson bacterial diversity QTL.

${ }^{\mathrm{z}}$ Each Simpson bacterial diversity QTL contained 12 to 15 adjacent map markers. Strength of association was calculated by dividing the number of markers with significant association with gene expression by the total number of adjacent map markers in the Simpson diversity locus. 
the two maize genotypes. Comparison of taxa contributing to genotype differences by SIMPER analysis indicated that a variety of different taxa contributed to genotype differences, rather than just one or two bacterial ribotypes (data not shown). Overall, SLB-resistant Mo17 leaves hosted a consistent set and large number of ribotypes, while the B73 genotype leaves hosted fewer bacterial types with more variation of the bacterial community across individual leaf samples.

\section{DISCUSSION}

Our study revealed consistent differences among maize genotypes in the diversity of the epiphytic microbial population and identified six loci, in map bins 1.06-1.07, 6.04-6.05, 9.05, 3.09, 7.03, and 9.06 that control epiphytic diversity. Strikingly, these loci had a significant overlap with maize loci controlling Southern leaf blight fungal disease resistance. Half the loci controlling Simpson diversity of epiphytic microbes were UV-B-specific, i.e., the B73 and Mo17 alleles at the locus were differently associated, with significant variation in phyllosphere diversity when exposed to UV-B radiation, but there was no significant association when UV-B was absent (allelic means are included in Supplemental Table 2). The other three QTL, in bins 3.09, 7.03, and 9.06 , were associated with allelic diversity both in the presence and the absence of UV-B. This allele-specific plasticity is often found in comparisons across environments (Lynch and Walsh 1998) although, in typical comparisons across field environments, there are many covarying abiotic factors. As we varied a single environmental factor, elucidation of the underlying mechanism and candidate gene selection under stress-specific QTL may be more straightforward (Campos et al. 2004; Edmeades et al. 2004).

We examined the available maize genome sequence (MaizeSequence website) in the QTL regions. Not all regions

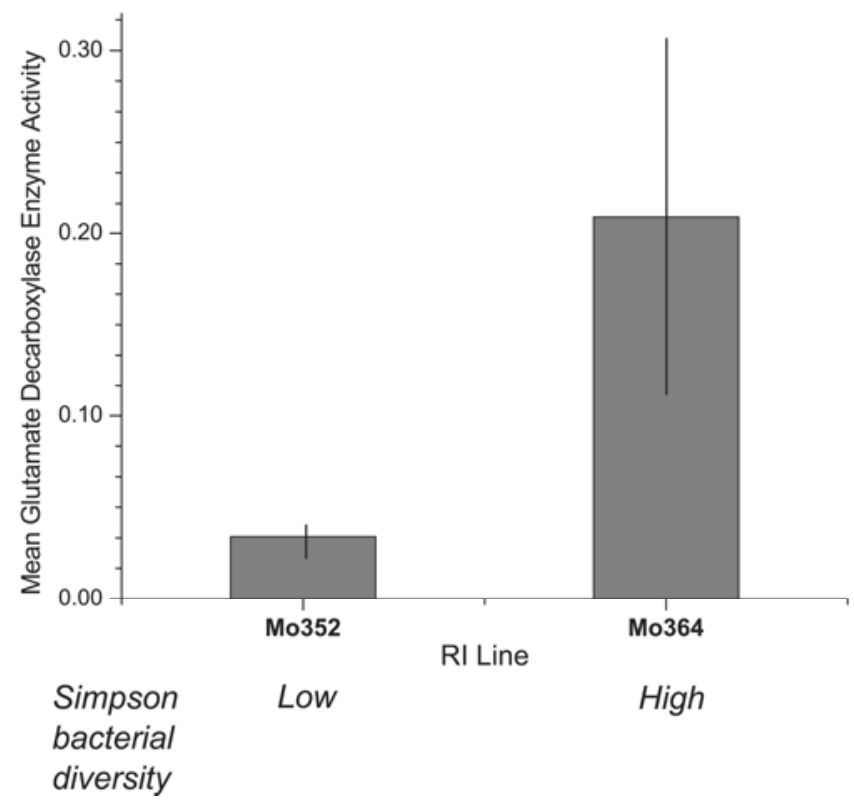

Fig. 3. Glutamate decarboxylase activity from field-grown leaf samples. Recombinant inbred (RI) lines without missing marker data and with uniform runs of B73 and Mo17 alleles at all the chromosome bin 1.06 Simpson-diversity quantitative trait loci markers were ordered by mean Simpson diversity, and the highest and lowest Simpson diversity RI lines were chosen for the field experiments. The high extreme line Mo364 had a Simpson diversity value of 0.95 , and the low extreme line Mo352 had a Simpson value of 0.59 . Glutamate decarboxylase activity was measured by amino-acid profiling. The confidence limits (vertical bars) were calculated by bootstrapping. Imputation and nonparametric analysis of variance gave $P=0.049$ for the comparison of activity ratio in these two RI lines. were annotated or available in the public genome data; however, one especially noteworthy candidate gene was located in the regions near 602 centiMorgan (cM) of chromosome 1, under a UV-B-specific QTL. This genomic region contains a gene annotated as a glutamate decarboxylase. Glutamate decarboxylases are the first step in the biosynthesis of GABA. In plants, GABA is induced by a variety of environmental stresses, and it has been proposed that extracellular plant-derived GABA plays an important role as a signaling molecule mediating plant interactions with a variety of organisms (Shelp et al. 2006). For example, GABA has been implicated in plant interactions with herbivorous insects (MacGregor et al. 2003), nematodes (McLean et al. 2003), pathogenic fungi (Oliver and Solomon 2004), bacteria (Chevrot et al. 2006), and communications with other plants via wound-induced volatile compounds (Mirabella et al. 2008). Based on these results in other systems and the genetic correlation observed in our studies, we hypothesize that UV-B from solar radiation alters glutamate decarboxylase activity and extracellular GABA levels which, in turn, affects epiphytic bacterial diversity and pathogen resistance when UV-responsive alleles are present. The comparison of glutamate decarboxylase activity between high and low Simpson-diversity lines planted in the field under ambient UV-B radiation (Fig. 3) is consistent with this hypothesis. Glutamate decarboxylase is known to be regulated by a variety of abiotic stresses and via calcium-calmodulin signaling (Forde and Lea 2007), and ultraviolet radiation was reported to have differential effects on expression of calcium-dependent kinases when B73 and Mo17 inbreds were compared (Blum et al. 2004).

This hypothesized role of glutamate decarboxylase could be tested by fine-mapping the QTL in chromosome bin 1.06 QTL to determine if it is localized at the candidate glutamate decarboxylase gene or by generation of mutations in the candidate gene. At present there are no mutations available in this glutamate decarboxylase gene in maize, so tests of the correlation between bacterial diversity and SLB resistance with and without this gene function would require mutant screening or construction of silenced transgenic maize lines.

Genes under Simpson-diversity QTL are more likely to be causal if they show significant allelic expression differences and the loci controlling those expression differences map to the same location as the gene themselves, i.e., are cis eQTL. We examined our maize eQTL data set, which was previously created from seedling leaves from the same mapping population, for expression array spots with significant associations with the sets of markers found in the diversity QTL regions (Table 1). In the bin 6.04 UV-B bacterial Simpson-diversity QTL region, the HVA22 gene was associated with a majority of the markers in the QTL region (association strength of 0.53 ). This gene is known to be stress-induced and functions in the regulation of vesicular traffic (Brands and Ho 2002), possibly in decreasing unnecessary cellular secretion. A role in interactions with cell-surface bacteria thus seems possible, and we list this as our top candidate gene under this QTL. The chromosome region defined by the chro-

Table 2. Multivariate distance (beta diversity) of leaf bacterial populations on inbred maize lines with antibiotic treatment ${ }^{z}$

\begin{tabular}{llc}
\hline Comparison & \multicolumn{1}{c}{ Level } & Average dissimilarity \\
\hline Line & B73 & $78.26 \mathrm{~A}$ \\
$\mathrm{P}_{\text {line }}=0.015$ & Mo17 & $52.17 \mathrm{~B}$ \\
Antibiotic treatment & High Strep & $71.98 \mathrm{a}$ \\
$\mathrm{P}_{\text {antibiotic }}=0.021$ & Low Strep & $79.45 \mathrm{a}$ \\
& No antibiotic (water) & $56.14 \mathrm{~b}$ \\
\hline
\end{tabular}

${ }^{\mathrm{z}} n=7$. Letters indicate groups significantly different in pairwise tests of levels within comparisons. 
mosome bin 7.02 diversity QTL has the strongest association with expression of a serine carboxypeptidase gene; this class of genes is associated with mobilization of nitrogen resources (Schaller 2004). A second strong association in this region is with SET gene expression; the SET-domain genes are involved in chromatin regulatory pathways ( $\mathrm{Ng}$ et al. 2007).

Comparison of our Simpson-diversity QTL with literature reports revealed intriguing overlaps with maize loci controlling SLB resistance in the field (Balint-Kurti et al. 2007). We calculated the probability of this overlap occurring by chance. As described by Wisser (2006), we used the maximum number of QTL detectable (325), which is calculated as median QTL size divided by total map distance. There are 11 loci for SLB overall (Balint-Kurti et al. 2007), and two of six overlap in the significant QTL list (Figs. 1 and 2), with five of 18 overlapping, if the suggestive QTL list is included. The probability of random draws matching our data is $P=0.0139$ for the two-of-six, and $P=0.000105$ for the suggestive Simpson-diversity QTL (equation given below). For both of the significant QTL and for three of the four overlapping suggestive QTL, the SLB resistance allele was the allele conditioning low Simpson bacterial diversity.

These overlapping SLB and Simpson bacterial diversity QTL are not found in experiments mapping SLB resistance in the greenhouse (Balint-Kurti and Carson 2006). This could be due to differences in the developmental stage of the plants, as previously suggested. An additional explanation for the differences in QTL between field and greenhouse could be that some allele interactions with UV-B are important for resistance. UV-B does not penetrate the greenhouse glass, and thus, the greenhouse-grown plants were not UV-exposed when tested for SLB resistance.

It should be noted that in four of the five suggested QTL that overlap for bacterial diversity and SLB resistance, the allele associated with SLB resistance is also associated with reduced bacterial diversity. Therefore, we can speculate that the re- duced bacterial Simpson diversity and restricted growth of $C$. heterostrophus on the leaf surface are functionally connected.

The genetic correlation between low phyllosphere diversity and disease resistance may be caused by underlying plant traits that $i)$ restrict colonization of the leaf surface by a diverse community of bacterial species and the development of SLB disease at the same time but with the pathogen and bacterial epiphytes not interacting with each other or ii) encourage the establishment, activity, or competitive ability of suppressive bacterial species suites, which reduces overall bacterial diversity and inhibits the growth of pathogenic strains. The antibiotic experiment tentatively supports model 2 , as antibiotic treatment increased leaf epiphyte beta diversity (variation in species present), thus suggesting that community diversity is limited by a relatively small number of antibiotic-susceptible microbial species. In this model (Fig. 4), we propose that the antibiotic reduced growth of the suite of suppressive bacteria and, therefore, increased bacterial beta diversity, even on a genotype such as Mo17 that normally supports a stable, consistent, bacterial community. In order to further test these models, additional tools for manipulating leaf microbial epiphytic populations and examination of correlations with leaf microstructure and nutrient and metabolite availability will be needed. If leaf structural or metabolic differences are the cause of the reduced pathogen growth, these leaf traits would make good breeding targets. If the underlying mechanism for disease resistance is based on traits that encourage establishment of beneficial bacterial species, selective enhancement of bacterial growth could be tested as a breeding target.

\section{MATERIALS AND METHODS}

Plant material.

The IBM advanced intercross RI lines (Lee et al. 2002) were supplied by the Maize Genetics Cooperation Stock Center in
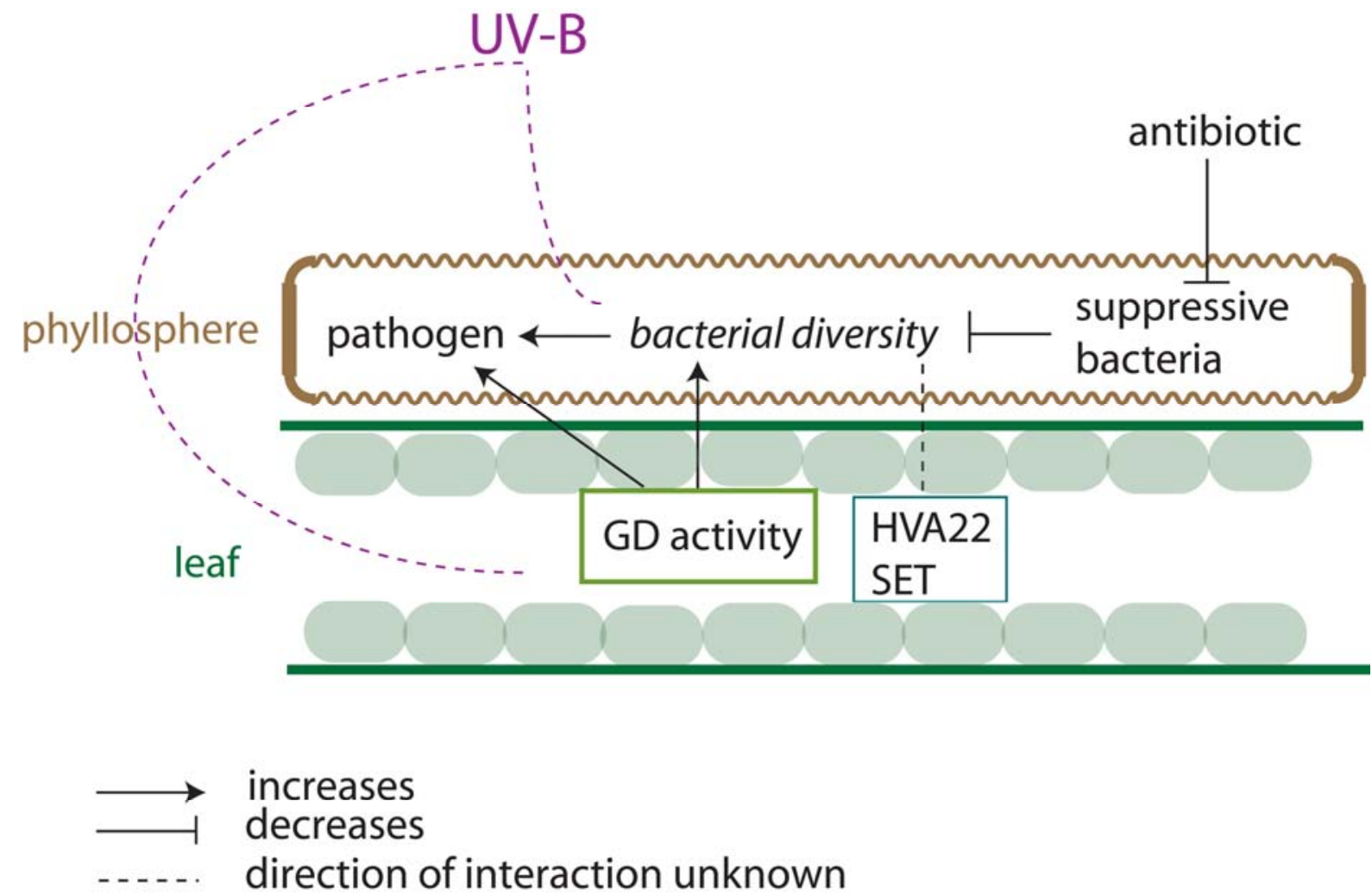

Fig. 4. Proposed model for microbial epiphyte-host leaf interactions. The phyllosphere with constituent microbes is shown above, with the host plant leaf indicated in the lower section. Rectangular boxes in the leaf indicate candidate important host plant proteins. 
2002, and seed was increased at the field nursery at the Central Crops Research Station, Clayton, NC, U.S.A. Genotypes of these specific seed lots in a subset of the lines were verified by amplification of 11 simple sequence repeat markers (Lee et al. 2002).

The maize parent inbred lines of the mapping population, B73 and Mo17, were used in the 2007 antibiotic field experiment. The inbred lines were supplied by the Maize Coop and increased in the Clayton field nursery.

\section{Field experiments.}

The QTL field experiment was carried out at IFEVA, Facultad de Agronomía, Buenos Aires, Argentina in January 2005; this site has been used for several physiological and ecological field ultraviolet radiation experiments (Caputo et al. 2006; Mazza et al. 1999). The field experiment setup used plants in soil-filled pots $(0.15 \mathrm{~m}$ diameter $)$ embedded in the soil underneath polychlorotrifluoroethylene (Aclar; Allied Signal Plastics, Morristown, NJ, U.S.A.) or polyester (Mylar-D; Du-Pont, Wilmington, DE, U.S.A.) filters. Aclar filters transmit visible, UV-A, and UV-B and Mylar filters transmit visible and UV wavelengths except for UV-B.

Pilot experiments indicated that variance within genotypes was important and adequate phyllosphere microbial DNA could be prepared from three plants. Given the limited space available under the field filters, we selected an experimental design with two filter-type blocks. Within each filter-type block, 36 genotypes, 34 RI lines, and the two parental inbred lines were represented; six pots per genotype were planted with three plants per pot, and pots were randomly distributed within each filter-type block. Seeds were germinated in wet paper towels, transplanted to pots, and then, grown under the field filters for 18 days to the five-leaf stage.

Inbred genotype comparisons were performed in the field nursery at the Central Crops Research Station in summer 2007. Plants were treated and harvested for microbial diversity measurements at growth stage V15 (seven weeks after planting). Genotypes were planted in sets of successive rows $(n=8$ rows), and three adjacent plants of each row were sprayed to runoff with streptomycin sulfate at $0.1 \mathrm{~g} /$ liter (low strep), 0.4 $\mathrm{g} /$ liter (high strep), or water (water control). Three days later, leaves were removed for microbial leaf community harvest. RI lines with genotypes at the two extremes of the observed microbial diversity (Mo352 and Mo364) were grown at the Clayton field site in two different fields separated by $1 \mathrm{~km}$ and harvested for enzyme assays in summer 2008; one field was uniformly inoculated with SLB, and the other had natural levels of inoculation (which are normally high at the Clayton site). Leaf tissue was collected and frozen at growth stage V15 (seven weeks after planting).

\section{Microbial community sampling.}

Leaf washes to collect phyllosphere microbes were performed essentially as previously described (Kadivar and Stapleton 2003; Stapleton and Simmons 2006). Plant leaves were cut and submerged in buffer $(0.2 \mathrm{mM}$ Tris, $\mathrm{pH} 7.5,0.02 \mathrm{mM}$ EDTA, $0.00012 \times$ Triton X100), were agitated vigorously and were removed. Mock samples (with no plants but otherwise following the harvest protocol) were collected at multiple points during harvesting. For the QTL experiment, the microbial fraction was collected on 0.02-micron sterile cellulose acetate filters, and then, the filter was removed and placed into the bead tube of an UltraClean Microbial DNA kit (MoBio, Carlsbad, CA, U.S.A.). The filter and tubes were frozen at $-70^{\circ} \mathrm{C}$ until DNA extraction. For the 2007 inbred genotype comparison, the sample's microbial fraction was collected by centrifugation at $13,000 \times g$ and was preserved in ethanol on ice until DNA extraction. The ethanol supernatant was added to the MoBio MD2 step as suggested by the manufacturer.

\section{Microbial DNA preparation and quantification.}

Phyllosphere genomic DNA was extracted using an UltraClean Microbial kit according to the manufacturer's instructions (MoBio). Blank samples (with extraction reagents but no leaf wash) were collected at several points throughout the extraction process. Genomic DNA was shipped to the University of North Carolina at Wilmington (Wilmington, NC, U.S.A.) for further analysis. Phyllosphere genomic DNA concentrations were measured with a Nanodrop 3300 spectrophotometer according to the manufacturer's instructions (NanoDrop, Wilmington, DE, U.S.A.) with standards and dyes from the Quant-IT HS kit (Invitrogen, Carlsbad, CA, U.S.A.).

\section{Microbial polymerase chain reaction $(\mathrm{PCR})$ and fragment detection.}

T-RFLP is a procedure in which variants of a single locus are PCR amplified and digested with a frequently cutting restriction enzyme. Different variants are identified by the size of their terminal restriction fragments. T-RFLP of the ribosomal DNA small subunit gene was carried out as described (Nunan et al. 2005). Reaction conditions and restriction enzyme selection were optimized using mixtures of genomic DNA from 10 bacterial species of known ribosomal sequence. Ribosomal DNA segments were amplified by PCR, using primers 63FAM (5'-AGGTAACACATGCAAGTC-3') with 5-carboyxyfluorocein and 1494r (5'-TACGGYTACCTTGTTACGAC-3'), synthesized by Integrated DNA Technologies (Coralville, IA, U.S.A.) in $15-\mu \mathrm{l}$ reactions with $2 \mathrm{ng}$ of genomic DNA and $0.5 \mathrm{U}$ AccuTaqLA polymerase (Sigma, St. Louis). The amplification program was 35 cycles of $94^{\circ} \mathrm{C}$ for $45 \mathrm{~s}, 55^{\circ} \mathrm{C}$ for $45 \mathrm{~s}$, and $72^{\circ} \mathrm{C}$ for $3 \mathrm{~min}$. Pilot analyses indicated that the most reproducible restriction digestion enzyme was $H$ haI, so the entire PCR reaction was restriction-digested with the HhaI enzyme (New England Biolabs, Ipswich, MA, U.S.A.) and was purified with AutoSeq G50 Sephadex columns (GE-Amersham, Piscataway, NJ, U.S.A.). Samples were dried under vacuum and were prepared for fragment analysis by the addition of $10 \mu \mathrm{l}$ of $\mathrm{HiDi}$ with ROX GS500 size standards (ABI, Foster City, CA, U.S.A.). An ABI 3100 Genetic Analyzer was used to separate and detect fragments, and GeneScan v.3.7 software was used to process raw fluorescent data and size standards.

For the 2007 field experiment, ARISA was used essentially as described (Cardinale et al. 2004). This method has greater sensitivity and accuracy than T-RFLP (Cardinale et al. 2004; A. E. Stapleton, unpublished results). Primers ITSF (5'-GTC GAACAAGGTAGCCGTA-3') and ITSReub (5'-HEX/GCCA AGGCATCCACC-3') were purchased from Integrated DNA Technologies. Amplifications were performed with Sigma AccuTaq DNA polymerase with $25 \mathrm{ng}$ of microbial genomic DNA per reaction. Amplified samples with ROX size standards were size-separated and detected on an ABI 3130 Genetic Analyzer. Genemapper software with Genescan emulation settings was used to process fluorescent data.

\section{Microbial diversity peak data analysis.}

As described by Abdo and associates (2006), processed peak data from each T-RFLP sample file was loaded into R (R Development Core Team 2005), using the perl script and binned to assign peaks to individual operational taxonomic units (species). T-RFLP will not distinguish all species in a sample; rare rDNA sequences will be missed due to assay sensitivity, and some species have identical T-RFLP ribotypes. Comparisons within experiments have less bias due to ribotype lumping, and selection of peaks by quality and appropriate bin ranges will 
reduce the possibility of bias due to missing rare sequences in samples. Diversity indices for each sample were calculated using the PAST program (Hammer et al. 2001). We used the Simpson index (1-Dominance) as our trait measurement for QTL analysis. This index was a good fit to a normal distribution by Q-Q plot analysis (JMP In; SAS, Cary, NC, U.S.A.). The Simpson index ranges from 0 to 1 , with larger values indicating higher diversity. ARISA peak data was processed using Ribosort (Scallan et al. 2007), using default parameters. A total of 550 peaks corresponding to 550 distinct ribotypes were detectable under our profiling conditions.

\section{QTL analysis.}

When marker patterns are already available, selective phenotyping can be used to maximize power for detection of QTL, if trait measurements are difficult and expensive (Jannink 2005; Vision et al. 2000). We selected the most informative subset of the RI mapping lines for our selective phenotyping experiment.

Analysis of the genetics of community structure presents statistical challenges both in the QTL analysis of the host and in the analysis of diversity measures in the microbial community. We selected a widely used index of diversity, the Simpson index (1-D), to generate the trait values for our QTL data analyses. This index has useful statistical properties, including known estimation of bias (Lande 1996). An index was necessary in order to do the quantitative trait analysis; methods for comparison of genotypes with varying chromosomal segments in common with multivariate diversity measures have not yet been developed (these methods are available for factorial experiments, as described in the antibiotic treatment data analysis section below). The median number of ribotypes detected by T-RFLP in a sample was 25 , with the range from 11 to 50 .

Two different methods were used to determine which chromosomal loci were associated with the diversity trait: i) linear modeling for each marker, with tests for marker association and for interaction between marker and ultraviolet radiation treatment, followed by $P$-value adjustments for genotype correlation structure and scan statistic adjustments to define significant loci, and ii) QTLNetwork software for composite interval mapping and for multiple environment analysis (Yang et al. 2008).

Markers. Marker genotypes for linear modeling included the full set of 4,678 markers available for the IBM94 RI line (Maize Genetics and Genomics database). In order to allow comparison to other work, the marker map locations from the most recent map build, IBM2 Neighbors 2005 (Schaeffer et al. 2006), were used for all analyses. Interval mapping cannot reliably utilize markers that are very close together, especially if the marker order is uncertain, as is the case with genetic maps. Thus, we used a reduced 2,421-marker set, generated by removing markers less than $1 \mathrm{cM}$ apart from the full marker list, for our QTLNetwork analysis. Markers with low $P$ values were tested for artificial coinheritance, as described previously (Williams et al. 2001). The maize genetic map is divided into 10 approximately equal bins per chromosome, which provides a way to easily locate and compare genome features such as QTL and gene families. Bins are indicated with the chromosome number dot bin number (e.g., 1.06).

Linear modeling and $\mathrm{P}-$ value adjustment. SAS v. 9.1 PROC GLM was used to calculate $P$ values for each marker and the probability of a significant treatment interaction effect for each marker. Raw $P$ values were sorted by chromosome location. It is not appropriate to use the false discovery rate for $P$-value adjustment at this marker density, given the correlated nature of markers along a chromosome (Chen and Storey 2006). As suggested by Sun and associates (2006b), we used the Zaykin rank method (Zaykin and Zhivotovsky 2005) to transform $P$ values. We used ChromoScan 1.0 to group $P$ values into significant regions (Sun et al. 2006a). ChromoScan settings of $P=$ 0.01 to enter the model and $P=0.01$ as minimal threshold for a region were used. At these conservative settings we are only able to detect QTL with effects greater the $20 \%$ of the mean in simulations. Suggestive QTL were detected using Penter $=0.05$.

QTLNetwork. The QTLNetwork software program integrates composite interval mapping methods with analysis of environmental effects (Yang et al. 2008). We used the default settings, except for selection of false discovery rate adjustment rather than permutation. The experiment-wise $P$-value threshold was set at $P=0.05$.

Probability calculations for QTL overlap. If QTL analysis is performed for two traits on the same population but using two independent phenotypic data sets, the likelihood QTL for two traits colocalizing just by chance can be calculated in the following way. If there are a total of 325 possible QTL (calculated as the map distance divided by the median QTL interval for that mapping population), and $x$ QTL are identified for one trait and 11 QTL are identified for the other trait, then the probability that the QTL colocalize is as follows.

$$
P(X=x)=\frac{\left(\begin{array}{c}
11 \\
x
\end{array}\right)\left(\begin{array}{c}
314 \\
11-x
\end{array}\right)}{\left(\begin{array}{c}
325 \\
11
\end{array}\right)}
$$

When $x=0$, there is no overlap in the QTL discovered in each lab. However, when $x=6$, there is complete overlap, and the six QTL discovered in one data set are a subset of the 11 discovered in the other lab.

Candidate gene searches in QTL locations. Version $3 \mathrm{~b} .50$ of the public maize genome sequence does not, at present, have a golden path, which means that the exact order of the sequenced bacterial artificial chromosomes (BAC) within each physically determined contig is not yet known. The QTL regions localized in our study encompass approximately 30 BAC each, with several genes per BAC. Thus, we examined regions under Simpson-diversity QTL by individual inspection of gene annotations for any text keywords relevant to pathogen interactions, abiotic stress, UV radiation responses, or bacterial symbiosis in all BAC in the QTL regions via the web browser.

\section{Prioritization of QTL candidate genes using eQTL information.}

Description of eQTL experiment. Maize RI lines were grown and exposed to ultraviolet radiation and were RNA extracted, labeled, and hybridized to spotted-oligo microarrays as described in the National Center for Biotechnology Information Gene Expression Omnibus database for accession GSE10544 and in supplemental data files for a study by Harjes and associates (2008).

Mixed model analysis of eQTL data. The full data set, with more than 53,000 spots for each replicate RI line under each treatment and the full set of 4,678 markers, was analyzed for significant marker expression-level association using a mixed model in SAS v. 8.2, with the data set divided among 40 individual computer processors to speed the analysis. As described by Cheverud (2001), we calculated the threshold chromosomewide $P$ value as $P<0.0002$ and retained only genes with a $P$ value less than the threshold in the final data matrix. The array gene ID numbers were matched to their genomic location (fpc contig), using a custom download from the MaizeSequence website (version 3b.50) that was provided by Cold Spring Harbor Laboratory (Cold Spring Harbor, NY, U.S.A.)

Criteria for selection of candidate genes under diversity QTL. Each diversity QTL region includes a set of 15 to 25 
markers that were used to locate significant marker-gene associations in our significant expression-by-marker data matrix. For each marker set under the QTL region, all genes with more than two significant markers were retained as candidates.

\section{Glutamate decarboxylase assay.}

The assay was adapted from Miyashita and Good (2008). A $1-\mathrm{cm}^{2}$ section of frozen leaf tissue was ground with a mortar and pestle in liquid nitrogen until powdered. Extraction buffer ( $1 \mathrm{ml} ; 100 \mathrm{mM}$ Tris, $\mathrm{pH}$ 7.5, $1 \mathrm{mM}$ EDTA, $10 \%$ glycerol, $1 \mathrm{mM}$ phenylmethylsulfonyl fluoride [Sigma]) was added, the mixture was centrifuged for $3 \mathrm{~min}$ at 9,000 rpm, and the supernatant was frozen for later analysis or added to assay buffer. For glutamate decarboxylase activity assays, $20 \mu \mathrm{l}$ of extract were added to $180 \mu \mathrm{l}$ of assay buffer $(150 \mathrm{mM}$ potassium phosphate, $\mathrm{pH} 5.8,10 \mathrm{mM}$ l-glutamic acid, $0.1 \mathrm{mM}$ pyroxidol-5-phosphate) and incubated at $21^{\circ} \mathrm{C}$ for $60 \mathrm{~min}$, and then, frozen for aminoacid analysis. Amino-acid analysis was carried out by the East Carolina University Amino Acid Analysis Core Laboratory (Greenville, NC, U.S.A.); a Beckman 6300 Amino Acid Analyzer with appropriate standards was used to determine the amount of amino acids in both the initial extract and the final assay aliquots from each leaf sample. As the amounts of amino acids differed in the extract as compared with the diluted assay, the ratio of GABA to Ala was used for comparison of glutamate decarboxylase activity between Mo352 and Mo364 leaf samples. The coefficient of variation for the glutamate decarboxylase assay averaged $28 \%$. The confidence interval for the mean activity ratio between genotypes was calculated by bootstrapping the measured ratios.

\section{Analysis of factorial genotype comparison data.}

Abundance data from Ribosort output files was tested for differences in homogeneity of multivariate dispersion, using the Bray-Curtis dissimilarity measure and a permutation-based method, permdisp (Anderson 2004). This provides a measure of beta diversity (Anderson et al. 2006) and guides the choice of test for location. If there are significant differences in dispersion, then analyses of location (mean) must be adjusted for the heterogeneity. Comparison of sample groups was carried out in PrimerE v. 6.0 (PRIMER-E Ltd, Ivybridge, U.K.), using ANOSIM two-way crossed analysis with replicates to test for differences in multivariate mean, with adjustment for dissimilarity, square root transformation, and Bray-Curtis distance, as suggested by the developer (Clarke and Gorley 2006). A SIMPER analysis was conducted in PRIMER-E to determine the relative contributions of each of the microbial species to the differences found on genotypes and after antibiotic treatment.

\section{ACKNOWLEDGMENTS}

A. E. Stapleton conceived of the study, grew the plants, collected the phyllosphere samples, carried out the tRFLP and ARISA assays, performed QTLNetwork and ChromoScan analyses, and wrote a draft of the manuscript. C. Ballaré hosted A. E. Stapleton in his lab, provided field space, and edited the manuscript. P. Balint-Kurti jointly designed the antibiotic and genotype experiment, planted the seed, performed the antibiotic treatment, and edited the manuscript. S. J. Simmons did the R analyses, probability calculations, and edited the manuscript. J. Blum wrote the GLM SAS code for QTL and eQTL analysis and edited the manuscript. We are grateful to the Ballaré lab members M. Izaguirre, C. Mazza, J. Moreno, M. Biondini, and W. de Nicolo for assistance with phyllosphere sampling. We appreciate the expert technical advice provided by $\mathrm{P}$. Fletcher and his generous support of our amino-acid analyses. We are grateful to C. Cowger and A. Belcher for reviewing this manuscript. The editor and reviewers provided thoughtful suggestions that greatly improved the manuscript. Assistance with sequence data and specially formatted maize sequence files were kindly provided by $\mathrm{S}$. Pasternak and D. Ware. This work was supported by National Science Foundation International grant \#OISE0436491 to A. E. Stapleton.

\section{LITERATURE CITED}

Abdo, Z., Schuette, U., Bent, S., Williams, C., Forney, L. J., and Joyce, P. 2006. Statistical methods for characterizing diversity in microbial communities by analysis of terminal restriction fragment length polymorphism of 16S rRNA. Environ. Microbiol. 8:929-938.

Anderson, M. J. 2004. PERMDISP: A FORTRAN computer program for permutational analysis of mutivariate dispersions (for any two-factor ANOVA design) using permutation tests. University of Auckland, Department of Statistics, Auckland, New Zealand.

Anderson, M. J., Ellingsen, K. E., and McArdle, B. H. 2006. Multivariate dispersion as a measure of beta diversity. Ecol. Lett. 9:683-693.

Baker, A. 2005. Briefing Room-Corn. United States Department of Agriculture Economic Research Service, Washington, DC.

Balint-Kurti, P. J., and Carson, M. L. 2006. Analysis of quantitative trait loci for resistance to southern leaf blight in juvenile maize. Phytopathology 96:221-225.

Balint-Kurti, P. J., Zwonitzer, J. C., Wisser, R. J., Carson, M. L., OropezaRosas, M. A., Holland, J. B., and Szalma, S. J. 2007. Precise mapping of quantitative trait loci for resistance to southern leaf blight, caused by Cochliobolus heterostrophus Race $\mathrm{O}$, and flowering time using advanced intercross maize lines. Genetics 176:645-657.

Ballaré, C. L., Scopel A. L., Stapleton A. E., and Yanovsky, M. J. 1996 Solar ultraviolet-B radiation affects seedling emergence, DNA integrity, plant morphology, growth rate, and attractiveness to herbivore insects in Datura ferox. Plant Physiol. 112:161-170

Beattie, G. S., and Lindow, S. E. 1999. Bacterial colonization of leaves: A spectrum of strategies. Phytopathology 89:353-359.

Blum, J. E., Casati, P., Walbot, V., and Stapleton, A. E. 2004. Split-plot microarray design allows sensitive detection of expression differences after ultraviolet radiation in the inbred parental lines of a key maize mapping population. Plant Cell Envir. 27:1374-1386.

Brands, A., and Ho, T. D. 2002. Function of a plant stress-induced gene, HVA22: Synthetic enhancement screen with its yeast homolog reveals its role in vesicular traffic. Plant Physiol. 130:1121-1131.

Campos, H., Cooper, M., Habben, J. E., Edmeades, G. O., and Schussler, J. R. 2004. Improving drought tolerance in maize: A view from industry. Field Crops Res. 90:19-34.

Caputo, C., Rutitzky, M., and Ballaré, C. L. 2006. Solar ultraviolet-B radiation alters the attractiveness of Arabidopsis plants to diamondback moths (Plutella xylostella L.): Impacts on oviposition and involvement of the jasmonic acid pathway. Oecologia 149:81-90.

Cardinale, M., Brusetti, L., Quatrini, P., Borin, S., Puglia, A. M., Rizzi, A., Zanardini, E., Sorlini, C., Corselli, C., and Daffonchio, D. 2004. Comparison of different primer sets for use in automated ribosomal intergenic spacer analysis of complex bacterial communities. Appl. Environ. Microbiol. 70:6147-6156.

Chen, L., and Storey, J. D. 2006. Relaxed significance criteria for linkage analysis. Genetics 173:2371-2381.

Cheverud, J. M. 2001. A simple correction for multiple comparisons in interval mapping genome scans. Heredity 87:52-58.

Chevrot, R., Rosen, R., Haudecoeur, E., Cirou, A., Shelp, B. J., Ron, E., and Faure, D. 2006. GABA controls the level of quorum-sensing signal in Agrobacterium tumefaciens. Proc. Natl. Acad. Sci. U.S.A.103:7460-7464.

Clarke, K. R., and Gorley, R. N. 2006. User manual/tutorial. PRIMER-E, Plymouth.

Compant, S., Duffy, B., Nowak, J., Clement, C., and Barka, E. A. 2005. Use of plant growth-promoting bacteria for biocontrol of plant diseases: Principles, mechanisms of action, and future prospects. Appl. Environ. Microbiol. 71:4951-4959.

De Costa, D. M., Pinto, M. T. C., Geethanjalee, H. D. N., and Dissanayake, N. 2006a. Suppression of rice pathogens by phyllosphere associated microflora of different rice varieties in Sri Lanka. Tropical Sci. 46:97-104.

De Costa, D. M., Rathnayake, R. M. P. S., De Costa, W. A. J. M., Kumari, W. M. D., and Dissanayake, D. M. N. 2006b. Variation of phyllosphere microflora of different rice varieties in Sri Lanka and its relationship to leaf anatomical and physiological characters. J. Agron. Crop Sci. 192:209-220.

de Jager, E. S., Wehner, F. C., and Korsten, L. 2001. Microbial ecology of the mango phylloplane. Microb. Ecol. 42:201-207.

Demoling, L. A., Baath, E., Greve, G., Wouterse, M., Schmitt, H. 2009. Effects of slufamethoxazole on soil microbial communities after adding substrate. Soil Biol. Biochem. 41:840-848

Edmeades, G. O., McMaster, G. S., White, J. W., and Campos, H. 2004. Genomics and the physiologist: Bridging the gap between genes and crop response. Field Crops Res. 90:5-18.

Everett, K. R., Vanneste, J. L., Hallett, I. C., and Walter, M. 2005. Ecological alternatives for disease management of fruit rot pathogens. N. Z. Plant Protect. 58:55-61.

Fiala, V., Glad, C., Martin, M., Jolivet, E., and Derridj, S. 1990. 
Occurrence of soluble carbohydrates on the phylloplane of maize (Zea mays L.): Variations in relation to leaf heterogeneity and position on the plant. New Phytol. 115:609-615.

Forde, B. G., and Lea, P. J. 2007. Glutamate in plants: Metabolism, regulation and signaling. J. Exp. Bot. 58:2339-2358.

Gau, A. E., Dietrich, C., and Kloppstech, K. 2002. Non-invasive determination of plant-associated bacteria in the phyllosphere of plants. Environ. Microbiol. 4:744-752.

Gunasekera T. S., and Paul N. D. 2007. Ecological impact of solar ultraviolet-B (UV-B : 320-290 nm) radiation on Corynebacterium aquaticum and Xanthomonas sp colonization on tea phyllosphere in relation to blister blight disease incidence in the field. Lett. Appl. Microbiol. 44:513-519

Gunasekera T. S., Paul N. D., and Ayres P. G. 1997. The effects of ultraviolet-B (UV-B:290-320 nm) radiation on blister blight disease of tea (Camellia sinensis). Plant Pathol. 46:179-185

Hammer, Ø., Harper, D. A. T., and Ryan, P. D. 2001. PAST: Paleontological statistics software package for education and data analysis. Palaeontol. Electron. 4:1-9.

Harjes, C. E., Rocheford, T. R., Bai, L., Brutnell, T. P., Kandianis, C. B., Sowinski, S. G., Stapleton, A. E., Vallabhaneni, R., Williams, M., Wurtzel, E. T., Yan, J., and Buckler, E. S. 2008. Natural genetic variation in lycopene epsilon cyclase tapped for maize biofortification. Science 319:330-333.

Heuer, H., and Smalla, K. 1999. Bacterial phyllosphere communities of Solanum tuberosum L. and T4-lysozyme-producing transgenic variants. FEMS (Fed. Eur. Microbiol. Soc.) Microbiol. Ecol. 28:357-371.

Hirano, S. S., and Upper, C. D. 2000. Bacteria in the leaf ecosystem with emphasis on Pseudomonas syringae-a pathogen, ice nucleus, and epiphyte. Microbiol. Mol. Biol. Rev. 64:624-653.

Ibekwe, A., and Grieve, C. 2004. Changes in developing plants microbial community structure as affected by contaminated water. FEMS (Fed. Eur. Microbiol. Soc.) Microbiol. Ecol. 48:239-248.

Idris, R., Trifonova, R., Puschenreiter, M., Wenzel, W. W., and Sessitsch, A. 2004. Bacterial communities associated with flowering plants of the Ni hyperaccumulator Thlaspi goesingense. Appl. Environ. Microbiol. 70:2667-2677.

Jannink, J. L. 2005. Selective phenotyping to accurately map quantitative trait loci. Crop Sci 45:901-908.

Johnson K. B., and Stockwell, V. O. 1998. Management of fire blight: A case study in microbial ecology. Ann. Rev. Phytopathol. 36:227-248

Kadivar, H., and Stapleton, A. E. 2003. Ultraviolet radiation alters maize phyllosphere bacterial diversity. Microb. Ecol. 45:353-361.

Karamanoli, K., Menkissoglu-Spiroudi, U., Bosabalidis, A. M., Vokou, D., and Constantinidou, H.-I. A. 2005. Bacterial colonization of the phyllosphere of nineteen plant species and antimicrobial activity of their leaf secondary metabolites against leaf associated bacteria. Chemoecology 15:59-67.

Kim, H., Nishiyama, M., Kunito, T., Senoo, K., Kawahara, K., Murakami, K., and Oyaizu, H. 1998. High population of Sphingomonas species on plant surface. J. Appl. Microbiol. 85:731-736.

Kinkel, L. L., Wilson, M., and Lindow, S. E. 2000. Plant species and plant incubation conditions influence variability in epiphytic bacterial population size. Microb. Ecol. 39:1-11.

Kliebenstein, D. 2009. Quantitative genomics: Analyzing intraspecific variation using global gene expression polymorphisms or eQTLs Ann. Rev. Plant Biol. 60:93-114.

Kniskern, J. M., Traw, M. B., and Bergelson, J. 2007. Salicylic acid and jasmonic acid signaling defense pathways reduce natural bacterial diversity on Arabidopsis thaliana. Mol. Plant-Microbe Interact. 20:1512-1522.

Lande, R. 1996. Statistics and partitioning of species diversity, and similarity, among multiple communities. Oikos 76:5-13.

Lee, M.-L. T., Sharopova, N., Beavis, W. D., Grant, D., Katt, M., Blair, D., and Hallauer, A. 2002. Expanding the genetic map of maize with the intermated B73 x Mo17 (IBM) population. Plant Mol. Biol. 48:453461

Lindow, S. E., and Brandl, M. T. 2003. Microbiology of the phyllosphere. Appl. Environ. Microbiol. 69:1875-1883.

Lindow, S. E., and Suslow T. V. 2003. Temporal dynamics of the biocontrol agent Pseudomonas fluorescens strain A506 in flowers in inoculated pear trees. Phytopathology 93:727-737

Lynch, M., and Walsh, B. 1998. Genetics and Analysis of Quantitative Traits. Sinauer Associates, Inc., Sunderland, MA

MacGregor, K. B., Shelp, B. J., Peiris, S., and Bown, A. W. 2003. Overexpression of glutamate decarboxylase in transgenic tobacco plants deters feeding by phytophagous insect larvae. J. Chem. Ecol. 29:2177-2182.

Marco, M. L., Legac, J., and Lindow, S. E. 2005. Pseudomonas syringae genes induced during colonization of leaf surfaces. Environ. Microbiol.
7:1379-1391.

Mazza, C. A., Zavala, J., Scopel, A. L., and Ballaré, C. L. 1999. Perception of solar UVB radiation by phytophagous insects: Behavioral responses and ecosystem implications. Proc. Natl Acad. Sci. U.S.A. 96:980-985.

McLean, M. D., Yevtushenko, D. P., Deschene, A., Van Cauwenberghe, O. R., Makhmoudova, A., Potter, J. W., Bown, A. W., and Shelp, B. J. 2003. Overexpression of glutamate decarboxylase in transgenic tobacco plants confers resistance to the northern root-knot nematode. Mol. Breed. 11:277-285.

Mercier, J., and Lindow, S. E. 2000. Role of leaf surface sugars in colonization of plants by bacterial epiphytes. Appl. Environ. Microbiol. 66:369-374.

Mirabella, R., Rauwerda, H., Struys, E. A., Jakobs, C., Triantaphylides, C. Haring, M. A., and Schuurink, R. C. 2008. The Arabidopsis her1 mutant implicates GABA in E-2-hexenal responsiveness. Plant J. 53:197-213.

Miyashita, Y., and Good, A. G. 2008. Contribution of the GABA shunt to hypoxia-induced alanine accumulation in roots of Arabidopsis thaliana. Plant Cell Physiol. 49:92-102.

Moody S. A., Newsham K. K., Ayres P. G., and Paul, N. D. 1999. Variation in the responses of litter and phylloplane fungi to UV-B radiation (290315 nm). Mycolog. Res. 103:1469-1477

Muller, A. K, Westergaard, K., Christensen, S., and Sorensen, S. J. 2002. The diversity and function of soil microbial communities exposed to different disturbances. Microb. Ecol. 44:49-58.

Newsham, K. K., Low, M. N. R., Greenslade, P. D., McLeod, A. R., and Emmett, B. A. 1997. UV-B radiation influences the abundance and distribution of phylloplane fungi on Quercus robur. New Phytol. 136:287297.

Ng, D. W. K., Wang, T., Chandrasekharan, M. B., Aramayo, R., Kertbundit, S., and Hall, T. C. 2007. Plant SET domain-containing proteins: Structure, function and regulation. Biochim. Biophys. Acta (BBA)-Gene Struct. Exp. 1769:316-329.

Nunan, N., Daniell, T. J., Singh, B. K., Papert, A., McNicol, J. W., and Prosser, J. I. 2005. Links between plant and rhizoplane bacterial communities in grassland soils, characterized using molecular techniques. Appl. Environ. Microbiol. 71:6784-6792.

Ojiambo, P. S., and Scherm, H. 2006. Biological and application-oriented factors influencing plant disease suppression by biological control: A meta-analytical review. Phytopathology 96:1168-1174.

Oliver, R. P., and Solomon, P. S. 2004. Does the oxidative stress used by plants for defence provide a source of nutrients for pathogenic fungi? Trends Plant Sci. 9:472-473.

Pancotto, V. A., Sala, O. E., Cabello, M., López, N. I., Robson, T. M. Ballaré, C. L., Caldwell, M. M., and Scopel, A. L. 2003 Solar UV-B decreases decomposition in herbaceous plant litter in Tierra del Fuego, Argentina: Potential role of an altered decomposer community. Global Change Biol. 9:1465-1474.

Picard, C., and Bosco, M. 2005. Maize heterosis affects the structure and dynamics of indigenous rhizospheric auxins-producing Pseudomonas populations. FEMS (Fed. Eur. Microbiol. Soc.) Microbiol. Ecol. 53:349-357.

Pierson, L. S., and Pierson, E. A. 2007. Roles of diffusible signals in communication among plant-associated bacteria. Phytopathology 97:227-232.

Piotrowska-Seget, Z., Engel, R., Nowak, E., and Kozdroj, J. 2008. Successive soil treatment with captan or oxytetracycline affects nontarget microorganisms. World J. Microbiol. Biotechnol. 24:2843-2848

Prosser, J. I., Bohannan, B. J. M., Curtis, T. P., Ellis, R. J., Firestone, M. K., Freckleton, R. P., Green, J. L., Green, L. E., Killham, K., Lennon, J. J., Osborn, A. M., Solan, M., van der Gast, C. J., and Young, J. P. W. 2007. The role of ecological theory in microbial ecology. Nat. Rev. Micro. 5:384-392.

R Development Core Team. 2005. R: A Language and Environment for Statistical Computing. R Foundation for Statistical Computing. Vienna, Austria.

Ramey, B. E., Koutsoudis, M., von Bodman, S. B., and Fuqua, C. 2004 Biofilm formation in plant-microbe interactions. Curr. Opin. Microbiol 7:602-609.

Robson T. M., Pancotto V. A., Ballaré C. L., Sala O. E., Scopel A. L., and Caldwell M. M. 2004. Reduction of solar UV-B mediates changes in the Sphagnum capitulum microenvironment and the peatland microfungal community. Oecologia 140:480-490

Scallan, U., Liliensiek, A., Clipson, N., and Connolly, J. 2007. RiboSort: A program for automated data preparation and exploratory analysis of microbial community fingerprints. Mol. Ecol. Res. 8:95-98.

Schaeffer, M. L., Sanchez-Villeda, H., McMullen, M., and Coe, E., Jr. . 2006. IBM2 2005 Neighbors-45,000 locus resource for maize. In: Plant and Animal Genome XIV, San Diego, CA U.S.A.

Schaller, A. 2004. A cut above the rest: The regulatory function of plant proteases. Planta 220:183-197. 
Schreiber, L., Krimm, U., Knoll, D., Sayed, M., Auling, G., and Kroppenstedt, R. M. 2005. Plant-microbe interactions: Identification of epiphytic bacteria and their ability to alter leaf surface permeability. New Phytol. 166:589-594.

Schweitzer, J. A., Bailey, J. K., Bangert, R. K., Hart, S. C., and Whitham, T. G. 2006. The role of plant genetic variation in determining aboveand belowground microbial communities. Pages 107-119 in: Microbial Ecology of Aerial Plant Surfaces. N. S. Iacobellis, A. Collmer, S.W. Hutcheson, J. W. Mansfield, C. E. Morris, J. Murillo, N. W. Schaad, D.E. Stead, G. Surico, and M. Ullrich, eds. Kluwer Academic CAB International, Dordrecht, The Netherlands.

Searles, P. S., Flint, S. D., Díaz, S. B., Rousseaux, M. C., Ballaré, C. L., and Caldwell, M. M. 1999 Solar ultraviolet-B radiation influence on Sphagnum bog and Carex fen ecosystems: First field season findings in Tierra del Fuego, Argentina. Global Change Biol. 5:225-234

Shelp, B. J., Bown, A. W., and Faure, D. 2006. Extracellular gammaaminobutyrate mediates communication between plants and other organisms. Plant Physiol. 142:1350-1352.

Smith, D. R., and White, D. G. 1988. Diseases of Corn. Pages 701-766 in: Corn and Corn Improvement, Agronomy Series \#18 (3rd ed.), C.F Sprague, and J.W. Dudley, eds. American Society of Agronomy-Crop Science Society of America-Soil Science Society of America, Madison, WI, U.S.A.

Smith, K. P., Handelsman, J., and Goodman, R. M. 1999. Genetic basis in plants for interactions with disease-suppressive bacteria. Proc. Natl. Acad. Sci. U.S.A. 96:4786-4790.

Stapleton, A. E., and Simmons, S. J. 2006. Plant control of phyllosphere diversity: Genotype interactions with ultraviolet-B radiation. Pages 223239 in: Microbial Ecology of Aerial Plant Surfaces. N. S. Iacobellis, A. Collmer, S.W. Hutcheson, J. W. Mansfield, C. E. Morris, J. Murillo N. W. Schaad, D. E. Stead, G. Surico, and M. Ullrich, eds. Kluwer Academic CAB Internationals, Dordrecht, The Netherlands.

Stockwell, V. O., and Stack, J. P. 2007. Using Pseudomonas spp. for integrated biological control. Phytopathology 97:244-249.

Sun, Y. V., Jacobsen, D. M., and Kardia, S. L. R. 2006a. ChromoScan: A scan statistic application for identifying chromosomal regions in genomic studies. BioInformatics 22:2945-2947.

Sun, Y. V., Levin, A. M., Boerwinkle, E., Robertson, H., and Kardia, S. L. R. 2006b. A scan statistic for identifying chromosomal patterns of SNP association. Genet. Epidemiol. 30:627-635.

Ullstrup, A. J. 1972. The impacts of the southern corn leaf blight epidemic of 1970-71. Ann. Rev. Phytopathol. 10:37-50.

Upper, C. D., Hirano, S. S., Dodd, K. K., and Clayton, M. K. 2003. Factors that affect spread of Pseudomonas syringae in the phyllosphere.
Phytopathology 93:1082-1092.

Vision, T. J., Brown, D. G., Shmoys, D. B., Durrett, R. T., and Tanksley, S. D. 2000. Selective mapping: A strategy for optimizing the construction of high-density linkage maps. Genetics 155:407-420.

Westergaard, K., Muller, A. K., Christensen, S., Bloem, J., Sorenson, S. J. 2001. Effects of tylosin as a disturbance on the soil microbial community. Soil Biol. Biochem. 33:2061-2071.

Whipps, J. M., Hand, P., Pink, D., and Bending, G. D. 2008. Phyllosphere microbiology with special reference to diversity and plant genotype. J. Appl. Microbiol. 105:1744-1755.

Whitham, T. G., Young, W. P., Martinsen, G. D., Gehring, C. A. Schweitzer, J. A., Shuster, S. M., Wimp, G. M., Fischer, D. G., Bailey, J. K., Lindroth, R. L., Woolbright, S., and Kuske, C. R. 2003. Community and ecosystem genetics: A consequence of the extended phenotype. Ecology 84:559-573.

Williams, R. W., Gu, J., Qi, S., and Lu, L. 2001. The genetic structure of recombinant inbred mice: High-resolution consensus maps for complex trait analysis. Genome Biol. 2:RESEARCH0046. Published online.

Wisser, R. J., Balint-Kurti, P. J., and Nelson, R. J. 2006. The genetic architecture of disease resistance in maize: A synthesis of published studies. Phytopathology 96:120-129.

Yang, C.-H., Crowley, D. E., Borneman, J., and Keen, N. T. 2001. Microbial phyllosphere populations are more complex than previously realized. Proc. Natl. Acad. Sci. U.S.A. 98:3889-3894.

Yang, J., Hu, C., Hu, H., Yu, R., Xia, Z., Ye, X., and Zhu, J. 2008. QTLNetwork: Mapping and visualizing genetic architecture of complex traits in experimental populations. BioInformatics 25:721-723.

Zaykin, D., and Zhivotovsky, L. 2005. Ranks of genuine associations in whole genome scans. Genetics 171:813-823.

\section{AUTHOR-RECOMMENDED INTERNET RESOURCES}

ChromoScanwebsite: www.epidkardia.sph.umich.edu/software/chromoscan

The Maize Genetics Cooperation Stock Center website: maizecoop.cropsci.uiuc.edu

Maize Genetics and Genomics database: www.maizegdb.org

The Maize Genome website: www.maizegenome.org

MaizeSequence website: www.maizesequence.org

The PAST (PAleontological STatistics) website: folk.uio.no/ohammer/past/index.html

The QTLNetwork software program ibi.zju.edu.cn/software/qtlnetwork/index.htm 